\title{
The Predictive Role of Emotional Intelligence on Personality and Shyness
}

\author{
Coşkun Arslan ${ }^{1}$, Ayşe Eliüşük Bülbül ${ }^{1, *}$, Çağla Girgin Büyükbayraktar ${ }^{2}$ \\ ${ }^{1}$ Department of Education Sciences, Konya Necmettin Erbakan University, Turkey \\ ${ }^{2}$ Department of Education Sciences, Selçuk University, Turkey
}

Copyright $\bigcirc 2017$ by authors, all rights reserved. Authors agree that this article remains permanently open access under the terms of the Creative Commons Attribution License 4.0 International License

\begin{abstract}
The main objective of this research is to determine the relationship between shyness, emotional intelligence and the five factor personality traits in university students. Furthermore it aims to determine whether the emotional intelligence and personality traits predict the Shyness levels at a significant level. The population of this study consisted of students from Bartın and Konya Necmettin Erbakan universities from which were 445 female and 172 male students with a total of 617 students. A random cluster sampling method was used in the selection of the sample. The age of the students ranged between 17 and 30 $\left({ }^{-}=19,25\right.$ and $\left.\mathrm{Ss}=.613\right)$. Bar-on emotional intelligence scale, the shyness scale and finally Adjective Based Personality Test (SDKT) used in order to determine five factorial personality traits of the students. As a result of the study; a positive relation found between university students' shyness and neuroticism and between personality traits; extraversion, openness, agreeableness and conscientiousness found to be negatively related. Between shyness and emotional intelligence, personal awareness, interpersonal relationships found a negative relationship between shyness and the general mood of the stress management and the compliance with the environment. Moreover it seen that personality traits and emotional intelligence were an important predictor of shyness.
\end{abstract}

Keywords Emotional Intelligence, Personality, Shyness

\section{Introduction}

Shyness continues to be a controversial subject within personality psychology. This is partly due to the acceptance of the term of everyday language, which has several different references, rather than a single definition. This is because the shyness can be analyzed with various components: cognitive I conceptual (in terms of self-awareness, prejudiced assessments of situations and self-referrals for social difficulties), emotional (anxiety, somatic reactions), and behavioral (withdrawn, withdrawn behaviors) components.
Crozier (2000) defines shyness as a state of disagreement with the continuity of one's individual or determined goals under one's individual circumstances. Shy / withdrawn temperament is characterized by extraordinary fear, contingency and timid behavior in foreign situations (Kagan et al., [24]) and shyness is one form of social withdrawal (Rubin and Asendorpf, [38] ). In another definition shyness is defined as "caution, anxiety and perceived social assessment in the face of social innovation" (Coplan et al., [6] ). From a slightly different perspective, "shyness" has been conceptualized as a (congenital) shy behavior in the context of social innovation or social assessments. It has been argued that shyness arises from a conflict of "approach avoidance" and sometimes referred to as contradictory shyness. It is a conflict of two simultaneous requests; social avoidance (i.e., a motivation for social avoidance) due to social fear and anxiety in a child because of a desire for social interaction (i.e., a social approach motivation) (Coplan and Rubin, [7]).

Shyness is associated with socially anxious people who have unrealistic negative self-assessments of their own social skills (Segrin and Kinney, [47]). Shyness also refers to emotional distress and withdrawnness which are typical for social situations (Van Ameringen et al., [49]). Moreover, shyness has been shown to be a valid indicator of loneliness, depression, social fear, and other physical and mental problems (Findlay et al., [14]; Schmidt and Fox, [45]). In addition, shyness is associated strongly and positively with fear and emotional loneliness (lack of close relationship), and negative self-esteem and optimism (Schmidt and Buss, [44]).

It is known that shyness is associated with timid behavior, especially during social interactions, and that such behavior is common throughout the development process. As early as two years after birth, about $10-15 \%$ of typical developing infants are continuously escaping and hiding constantly from people, objects and situations which are unfamiliar to them (Fox et al., [15]). As shy children grow up, their shyness may be the core of their personality and their own understanding and they consider themselves "shy". They also handle with 
their shyness by means of ways that prevent them from overcoming their shyness. Testing the hypotheses about the social effects of shyness requires proper precautions and these have been developed within a framework of personality understanding (Crozier, [10]).

Shy persons are reluctant to socialize because of the fear of lack of their social competence and fear of being rejected by others (Jackson et al., [22]). Shyness is a common and problematic situation for withdrawn persons, which they want to get rid of (Carducci and Zimbardo, [4]). Shy persons sometimes show facial flushes or physical sensations such as being unable to speak, trembling or shortness of breath. They usually hesitate before trying something new and prefer to watch others before joining a group activity. It usually takes longer to come closer to new people and situations, and it has been determined that this happened in the highest level in adolescence (Simmons and Rosenberg, [48]).

Schmidt $(1999,2003)$ argued that the origins of shy and social personality types may be related to the tendency for psychological conflict in social settings, which underlie the approach-avoidance tendencies, or to differences that result in the perception of these situations. The appearance of antisocial and problematic behaviors in shy and social individuals may be the result of failures in coping with stress. Persons who are both anxious and social are described as "social-conflicting" by Schmidt. According to McCrae and Costa (1999); shy individuals responded to their environment by changing their thoughts, emotions and behavior patterns which are consistent with their personalities. There is a tight relationship between shyness and personality. Therefore, it would be appropriate to define the personality, which is another variable in our study.

People's attitudes, beliefs, perceptions and behaviors are partly created by their personalities; to put it another way, these psychological trends have fundamental effects on a number of variables of the person. Personality determines the nature of each person and defines the unique aspects and characteristics which are reflected in all our thoughts and actions. As features play a general role in people's perception and behavior, it is reasonable to expect that personality play a part in processes and outcomes related to a number of individual characteristics (Devaraj et al., [11]). Personality psychologists have worked a long to establish an integrative and descriptive taxonomic model that will define important dimensions of personality in personality research (Dietrich et al., [12]; McCrae and John, 1992). The Five Dimensional or Five-Factor Model of Personality (FFM) is defined by a number of studies conducted in different cultures and various methods of information gathering. Factor analysis revealed a fairly accurate personality set. Five dimensions are built up solidly in ongoing research efforts in the field of personality (Costa and McCrae, [8]). Factors often consist of personality descriptors that define broad personality dimensions that are interpreted as extraversion / withdrawnness or promotion, agreeableness or friendly / enmity, conscientiousness, neurotics / emotional stability and openness (Digman, [13];
John et al., [23]).

Despite the Five Factor Model (FFM), defined by extraversion, agreeableness, neuroticism and openness dimensions, is a system that is highly acclaimed in the last decade (McCrae and John, [34]), the Great Five features are consistently found using different research methods and are considered genetically rooted, stable, and to be generalized cross-culturally (McCrae and Costa, [33]; Saucier et al., [41]). The five main personality traits of the Five-Factor Model (FFM) are: Neuroticism (N): vulnerability / sensitivity towards individual awareness and neuroticism; Extraversion (E): susceptibility to sociability, enterprise and social interaction; Openness (O): cognitive / perceptual predisposition to creativity and aesthetics; Agreeableness (A): a tendency to be sympathetic, reliable and self-sacrificing; Conscientiousness(C): ability to know responsibility and competence (Costa and McCrae, [9] ). We we look closer to the features; Extraversion (E), active dialogue, sociable in games, humorous, energetic, agile personal tempo, enthusiastic facial expression, gestures, extroverted attitudes, communicative and friendliness, Agreeableness (A); caring, not critical or skeptical, generous and sympathetic forgiving attitudes, thoughtful, gentle, warm sympathetic, compassionate, basically reliable; Conscientiousness (C): efficient, reliable, productive, organized, responsible; performing the tasks, scheduled, able to delay comfort/passion, trustable, not comfortable, ethically responsible behaviors and someone who owns a comprehensive high objective; Neuroticism $(\mathrm{N})$ : anxious, emotional, self-pitying, fragile ego defenses, tense, self-inhibiting, basically anxious, irritable, uncertain about competence, worrying fluctuating moods, Openness $(\mathrm{O})$ : A wide range of artistic interests, curious, insightful, creative, extraordinary thought processes, comprehensible values, intellectual issues, original judgments in unconventional terms, broad interests, aesthetic responses (McCrae and John, [34]). A study of Goldberg (1992) showed that the five factor structure of personality is evident in adults and university students.

Shyness is not only related to personality traits but also to emotional intelligence. Emotional intelligence has a negative relationship with shyness. İt was also found that emotional intelligence affects shyness and that students with high emotional intelligence do experience less shyness. There is a negative relationship between emotional intelligence characteristics and shyness rates and it is revealed that students with high emotional intelligence experience less shyness (Montazergheib and Ahghar, [35]; Hajloo and Farajian, [20]). Similar studies have shown that high emotional intelligence is closely related to social skills and emotional intelligence and socialization due to socialization are closely related (Basteen et al., [2]; Schutt and Malouff, [46]; Mayer et al, [25]). From this point of view it will be reasonable for us to make the definition of emotional intelligence.

Emotional intelligence is a set of skills that includes 
perception of feelings both for others and for oneself, facilitating performances using emotions, understanding emotions and emotional intelligence and regulating emotions in others and themselves (Mayer and Salovey, [28]. As a feature, emotional intelligence is also called emotional self-efficacy and is described as a whole of emotional self-perception that is at lower levels of personality hierarchies (Petrides et al, [37]). Another definition of emotional intelligence is the management of emotions. Management of a person is the result of an adaptable system that measures, evaluates and when necessary, responds to specific features (Mayer and Gaschke, [26]). Emotional intelligence is a component of social intelligence. It is also defined as to track emotions, to differentiate between different emotions and the ability to apply these behaviors, information, thoughts and actions (Salovey and Mayer, [40]) Salovey and Mayer (1990) justify the naming of emotional intelligence, because the processing of certain emotional information in the organism and the competence in these skills are necessary for adequate social functioning. To evaluate and express oneself and others; regulate emotions in oneself and others, reaching goals using emotions are mental processes by which is emotional intelligence used. The structure of emotional intelligence meets the conceptual, relational, and developmental criteria of intelligence, based on their intelligence research suggested by Mayer, Caruso and Salovey (2000). When describing the conceptual criterion of intelligence; the structure must reflect its ability to behave in a certain way (Carroll, [5]). Goleman (2005) suggests that everyone has the potential to learn and improve how to reveal the own emotional intelligence. Goleman (2005) also believes that emotional intelligence skills are necessary and practicable in professional and personal efforts and that gaining mastery in these skills do increase the potential for success.

It is believed that the role of emotional intelligence on personality is similar to the role played by traditional analytical intelligence. In particular, emotional intelligence is an interconnected skill sequence that allows people to process emotionally relevant information efficiently and accurately (Mayer et al., [25]). Maybe emotional intelligence would be social awareness, a competency in that would be empathy or service (Goleman et al., [17]). From another point of view; some researchers claimed that emotional intelligence is a different structure than personality (Mayer et al., [25]) and others used personality tests to isolate the effect of emotional intelligence in their studies (Higgs and Aitken, [21]). Emotional intelligence and personality factors are positively related to personal awareness, interpersonal sensitivity and conscientiousness, especially in Higgs and Aitken's (2003) studies. Mayer et al. (2008) have described the big five as neuroticism, extraversion, openness, agreeableness and conscientiousness. The consideration of the Big Five is important to ensure that emotional intelligence is a real intelligence and not a combination of one or more personality features within the Big Five.

Mayer et al. (1990) defined emotion while researching personality. From this point; further research is needed to clarify the relationship between personality traits like the Big Five and emotional intelligence and shyness. Because of this need, we aimed to research the relationship between shyness, emotional intelligence and the dimensions of the five-factor model. There are only a few studies in Turkey and in the world that are currently investigating these associations (Bratko et al., [3]; Montazergheib and Ahghar, [35]; Hajloo and Farajian, [20]; Ryan and Xenos, [39]). From this point of view, it is thought that the literature will contribute considerably.

\section{Materials and Methods}

\section{Model of the Study and Study Group}

An appropriate sampling method has been adopted to determine the study group of the research. Appropriate sampling is a sampling method based on data collection on nearby volunteers who are easy to reach and in the immediate vicinity (Cohen, Manion, \& Morrison, 2013).

The study's population consisted of students who are studying in Bartın University Science, Primary Education Religion and Ethics, Mathematics, Social Studies and Turkish Language Teaching departments and Selcuk University Child Development and Pre-School Teachers departments. The study group of the research consisted of 445 females, 172 males with a total of total 617 students. A random cluster sampling method was used in the selection of the sample. The students were between the ages of 17-30 $\left(^{-} \mathrm{x}\right.$ $=19,25$ and $\mathrm{Ss}=.613$ ).

\section{Data Collection Tools}

Emotional Intelligence Scale: Surveys were used as data collection tools in the research. Emotional intelligence was measured using the emotional intelligence scale developed by Bar-On (2001). The original state of this scale consists of five sub-dimensions including personal awareness, interpersonal relationship, harmony with the environment and circumstances, stress management and general mood and 88 expressions in total. The adaptation of the scale into Turkish was done by Mumcuoğlu (2002).

Shyness scale: This scale was developed by Cheek (1990) and adapted to Turkish by Güngör (2001). The validity of the "Shyness Scale" were found (.96) and the reliability was found (.88). It is a 5 Likert type scale and this shyness scale consists of 20 items. The highest score that can be obtained from the scale is 100 and the lowest score is 20 . A high score indicates that the individual perceives himself as "shy".

Adjective-Based Personality Test (SDKT) (Bacanl, Ilhan \& Arslan, [1]): The Adjective-Based Personality Test was developed by Bacanlı \& İlhan and Arslan [1]. The SDKT consists of five sub-dimensions (Neuroticism, extroversion, openness to experience, empathy, conscientious). In order to test the structure validity of the SDKT, Principal Components Factor Analysis was performed on the data 
obtained from 285 participants. As a result of the analysis, five factors revealed $52.63 \%$ of the variance belonging to SDKT. Sociotropy Scale, Conflict Response Scale, Negative-Positive Feeling Scale, Continuous Anxiety Inventory were used to test the concordance validity of the SDKT. When examined in general, it has been found that the dimensions of SDKT are moderate and meaningful with the scales used for concordance validity, and that these results are important in terms of concordance validity. Within the reliability studies of SDKT, the internal consistency coefficients of the instrument were calculated on the data obtained from 285 participants and SDKT was applied to 90 participants with an interval of two weeks. The internal consistency coefficients of the dimensions of SDKT were found to vary between .73 and .89 . When the findings related to the SDT test repetition were examined, it was found that the highest associations were the Agreeableness $\left(\mathrm{r}=.86^{* *}, \mathrm{p}\right.$ $<.01)$ and the lowest relationship was the Openness to Experience dimension $(\mathrm{r}=.68 * *, \mathrm{p}<.01)$.

\section{Conclusions}

Before the analysis, it was tested whether the data showed a normal distribution. For this purpose, the skewness and kurtosis values on the distributions of the total scores obtained from the scales were examined and the values obtained as the calculation results are given in Table 1.
When the values given in Table 1 are examined, it can be seen that the coefficients of skewness and kurtosis calculated for each factor of the Emotional Intelligence Scale, Shyness Scale and Adjective-Based Personality Inventory are within -1.5 to +1.5 limits, shows that the scores of the factors are within normal distribution (Tabachnick \& Fidell, 2001). As a result, it was decided to use parametric tests on the data obtained from the scales.

In this context; descriptive statistics, correlation analysis and regression analysis were used to determine the differences between the two groups in the analysis of the data collected from the scales.

Findings: The Pearson Moments Correlation technique was first used in the study to reveal the relationship between emotional intelligence and shyness. The results are given in Table 1 and Table 2.

There was a significant positive correlation between shyness and neuroticism as a personality trait in Table 2 $\left(\mathrm{r}=185^{* *}\right)$. The second sub-dimension of personality traits, the extraversion, was found to be significantly related with shyness in the negative direction $\left(\mathrm{r}=-, 391^{* *}\right)$. Another sub-dimension, the openness, had a significant negative correlation to shyness $\left(\mathrm{r}=-, 315^{* *}\right)$. There was a significant negative correlation between agreeableness as a personality trait and shyness $\left(\mathrm{r}=-, 088^{*}\right)$. There was a significant negative correlation between conscientiousness, the final dimension of personality traits and shyness $\left(\mathrm{r}=-, 113^{* *}\right)$.

Table 1. Skewness and kurtosis coefficients of scale factors

\begin{tabular}{|c|c|c|c|}
\hline \multirow{2}{*}{ Scale } & Sub-dimension of the scale & Skewness & Kurtosis \\
\hline \multirow{4}{*}{ Emotional Intelligence } & Personal awareness & $1,330(\mathrm{SH}=, 168)$ & $1,091(\mathrm{SH}=, 334)$ \\
\cline { 2 - 4 } & Interpersonal relationships &, $913(\mathrm{SH}=, 168)$ &, $224(\mathrm{SH}=, 334)$ \\
\cline { 2 - 4 } & Compliance with conditions and environment &, $085(\mathrm{SH}=, 168)$ &,$- 304(\mathrm{SH}=, 334)$ \\
\cline { 2 - 4 } & Stress management &, $075(\mathrm{SH}=, 168)$ &,$- 404(\mathrm{SH}=, 334)$ \\
\cline { 2 - 4 } & General mood &, $906(\mathrm{SH}=, 168)$ &, $124(\mathrm{SH}=, 334)$ \\
\hline \multirow{4}{*}{ Personality traits } & Neuroticism &, $008(\mathrm{SH}=, 168)$ &,$- 441(\mathrm{SH}=, 334)$ \\
\cline { 2 - 4 } & Extraversion &,$- 168(\mathrm{SH}=, 168)$ &,$- 096(\mathrm{SH}=, 334)$ \\
\cline { 2 - 4 } & Openness &, $045(\mathrm{SH}=, 168)$ &,$- 695(\mathrm{SH}=, 334)$ \\
\cline { 2 - 4 } & Agreeableness &, $073(\mathrm{SH}=, 168)$ &,$- 682(\mathrm{SH}=, 334)$ \\
\cline { 2 - 4 } & Conscientiousness &, $953(\mathrm{SH}=, 168)$ &,$- 582(\mathrm{SH}=, 334)$ \\
\hline Shyness & Shyness & $\mathrm{SH}=, 168)$ & $-224(\mathrm{SH}=, 334)$ \\
\hline
\end{tabular}

Table 2. Relationship between Shyness and Personality traits

\begin{tabular}{|c|c|c|c|c|c|c|}
\hline \multicolumn{2}{|l|}{} & Neuroticism & Extraversion & Openness & Agreeableness & Conscientiousness \\
\hline Shyness & $\mathrm{r}$ &, $185^{* *}$ &,$- 391 * *$ &,$- 315^{* *}$ &,$- 088^{*}$ &,$- 113^{* *}$ \\
\hline
\end{tabular}

**p $<.01, * \mathrm{p}<.05$,

Table 3. The Relationship between Shyness and Emotional Intelligence

\begin{tabular}{|c|c|c|c|c|c|c|}
\hline \multicolumn{2}{|l|}{} & Personal awareness & $\begin{array}{c}\text { Interpersonal } \\
\text { relationships }\end{array}$ & $\begin{array}{c}\text { Compliance with conditions } \\
\text { and environment }\end{array}$ & $\begin{array}{c}\text { Stress } \\
\text { management }\end{array}$ & General mood \\
\hline Shyness & $\mathrm{r}$ &, $412^{* *}$ &, $183^{*}$ &, $266^{* *}$ &, $142^{*}$ &, $290^{* *}$ \\
\hline
\end{tabular}

**p $<.01, * \mathrm{p}<.05$ 
When Table 3 is examined, it can be seen that there was a significant positive correlation between self-awareness as a sub-dimension of emotional intelligence and and shyness $\left(\mathrm{r}=, 412^{* *}\right)$. The second sub-dimension of emotional intelligence, the interpersonal relationship was lowly positively correlated with shyness $\left(\mathrm{r}=, 183^{*}\right)$. There was a positive correlation between the other sub-dimension, compliance with conditions and environment and shyness $\left(\mathrm{r}=, 266^{* *}\right)$. There was a low positive correlation between stress management, which is another sub-dimension of emotional intelligence and shyness $(\mathrm{r}=, 142 *)$. There was a moderate negative correlation $\left(\mathrm{r}=-, 290^{* *}\right)$ between shyness and general mood as the last dimension of emotional intelligence. The fact that the correlation coefficient, as an absolute value, was between 0.70 and 0.10 , highly between 0.70 and 0.30 , moderate between; $0.30-0.00$ was considered as a low level relationship (Büyüköztürk, 2012).

When Table 4 is examined, multiple regression analysis results are given to predict the level of shyness from emotional intelligence and personality traits. When examined how the emotional intelligence do predict shyness; it was seen that emotional intelligence alone accounts for $18 \%$ of shyness and was regarded as an important predictor of shyness $\left(\mathrm{R}=.44, \Delta \mathrm{R}^{2}=. .18, \mathrm{~F}=21.295, \mathrm{p}<001\right)$. It was found that emotional intelligence was an important predictor of interpersonal relationships $(\beta=-.20 p<.001)$, compliance with conditions and environment $(\beta=.09, p<.001)$ and self-awareness $(\beta=.43, p<.001)$ sub-dimensions. It was seen that in the second step of the model, emotional intelligence as well as five factor personality traits were found to be a significant contributor to the model and that emotional intelligence together with personality traits are accounting for $33 \%$ of shyness. The personality trait item which predicts shyness strongly was found to be neuroticism $(\beta=.24, p<.001)$, extraversion $(\beta=-.38, p<.01)$, openness $(\beta=-.21, \quad p<.001)$ and agreeableness $(\beta=.25$, $\mathrm{p}<.001)$.

Table 4. Multidimensional hierarchical regression analysis on shyness

\begin{tabular}{|c|c|c|c|c|c|c|c|c|c|}
\hline & & $\mathrm{R}$ & $\mathrm{R}^{2}$ & $\Delta \mathrm{R}^{2}$ & $\mathrm{~F}$ & Df & Beta & $\beta$ & $\mathrm{P}$ \\
\hline & Stable & & & & & & & 18.111 & .00 \\
\hline \multirow[t]{5}{*}{1} & Personal awareness & .44 & .19 & .18 & 21.295 & $5 / 447$ & .43 & .52 & .00 \\
\hline & Interpersonal relationships & & & & & & -.20 & -.34 & .00 \\
\hline & $\begin{array}{c}\text { Compliance with conditions and } \\
\text { environment }\end{array}$ & & & & & & .09 & .25 & .00 \\
\hline & Stress management & & & & & & -.05 & -.11 & .12 \\
\hline & General mood & & & & & & .11 & .27 & .30 \\
\hline \multirow[t]{11}{*}{2} & Stable & & & & & & & 34.266 & .00 \\
\hline & Personal awareness & .59 & .35 & .33 & 23.214 & $10 / 447$ & .29 &, 343 & .00 \\
\hline & Interpersonal relationships & & & & & & -.14 & -.23 & .02 \\
\hline & $\begin{array}{c}\text { Compliance with conditions and } \\
\text { environment }\end{array}$ & & & & & & .10 & .27 & .06 \\
\hline & Stress management & & & & & & -.05 & -.10 & .33 \\
\hline & General mood & & & & & & .00 & .00 & .99 \\
\hline & Neuroticism & & & & & & .24 & .50 & .00 \\
\hline & Extraversion & & & & & & -.38 & -.57 & .00 \\
\hline & Openness & & & & & & -.21 & -.37 & .01 \\
\hline & Agreeableness & & & & & & .25 & .38 & .00 \\
\hline & Conscientiousness & & & & & & .10 & .21 & .10 \\
\hline
\end{tabular}




\section{Discussion}

The findings between shyness and personality traits were as follows: when looking at the relationship between emotional intelligence, personality traits and shyness of university students; it was seen that there were a positive relationship between shyness and neuroticism as a personality trait and a significant negative correlation was seen between shyness and the extraversion, openness, agreeableness and conscientiousness dimensions. In addition, regression analysis revealed that emotional intelligence as well as the five-factor personality traits contributed significantly to the model, while emotional intelligence and personality traits revealed $33 \%$ of the shyness. Bratko et al. [3] find similar to our study that shyness is significantly associated with the sociability, neuroticism and extraversion dimensions. The neuroticism dimension of the five-factor personality model is found to be the best predictor of shyness. Extraversion is found to be an important predictor of shyness, both in girls and boys. Ryan and Xenos (2011) reveal in their study that all of the personality traits of Facebook users are significantly related to their Facebook preferences. According to McCrae and Costa (1997); shy individuals respond to their environment by changing their thoughts, emotions and behavior patterns which are consistent with their personality. Therefore, they expected that the shy individuals will be related to the dimensions of the five-factor model due to their responsibility characteristics. Schmidt $(1999,2003)$ also claimed that the origins of the shy and social personality types may be related to the tendency to psychological conflict in the social environment, which underlies the approach-avoidance tendencies, or to differences that result in the perception of these situations. The appearance of antisocial and problematic behaviors in shy and social individuals may be the result of failures in coping with stress. Both anxious and social individuals are described as "social-conflicting" by Schmidt.

Findings about shyness and emotional intelligence are as follows: there was a positive relation between shyness and the sub-dimensions of emotional intelligence, which are personal awareness, interpersonal relationships, compliance with circumstances and environment, stress management; and a significant negative relationship between shyness and general mood. In addition; to see if shyness and personality traits could explain emotional intelligence at a meaningful level, a multidimensional hierarchical regression analysis revealed that emotional intelligence alone accounts for $18 \%$ of shyness and is an important predictor of shyness. Montazergheib and Ahghar (2010) are found similar findings in their study: emotional intelligence is negatively associated with shyness, and emotional intelligence is found to be a significant predictor of shyness. They also find that emotional intelligence affected shyness and that students with high emotional intelligence experienced less shyness. Another study from Montazergheib and Ahghar (2010) find a negative relationship between university students' emotional intelligence and shyness rates. The found that shyness is an important predictor of emotional intelligence and students with high emotional intelligence showed less shyness. Hajloo and Farajian (2013) is shown in their work that shyness predicts in a significant way the emotional intelligence. The study emphasizes the importance of self-awareness; self-management and relationship management is not sufficient and has to be empowered in shy people. Ryan and Xenos (2011) found in their study about facebook users that those who do not use Facebook are more likely to be shyer and socially lonely. Similar studies is also shown that high emotional intelligence is closely related to social skills and a close relationship between emotional intelligence and socialization is established (Basteen et al., [2]; Schutl and Malouff, 2001; Mayer et al., [25]).

\section{REFERENCES}

[1] Bacanlı, H. İlhan, T. \& Aslan, S. (2009). Beş Faktör Kuramına Dayalı Bir Kişilik Ölçeğinin Geliştirilmesi: Sıfatlara Dayalı Kişilik Testi (SDKT).Türk Eğitim Bilimleri Dergisi,7(2): 261-279.

[2] Basteen, E.J. Bern, D. \& Bek, V. (2005). Personality, well-being, and health correlates of trait emotional intelligence. Personality and Individual Differences, 38: 547-558.

[3] Bratko, D. Vukosav, Z. Zarevski, P. \& Viranic, A. (2002). The Relations of shyness and assertiveness traits with the dimensions of the five-factor model in adolescence. Review of Psychology, 9(1-2): 17-23.

[4] Carducci, B.J. \& Zimbardo, P. (1995). Are you shy? Psychology Today, 64: 34-40.

[5] Carroll, J.B. (1993). Human Cognitive Abilities: A Survey of Factor-Analytic Studies. New York: Cambridge University Press.

[6] Coplan, R.J. Girardi, A. Findlay, L.C. \& Frohlick, S. L. (2007). Understanding solitude: Young children's attitudes and responses to hypothetical socially withdrawn peers. Social Development, 16: 390-439.

[7] Coplan, R.J. \& Rubin, K. H. (2010). Social Withdrawal and Shyness in Childhood: History, Theories, Definitions, and Assessments. The Development of Shyness and Social Withdrawal (Ed. Coplan, R. J. \& Rubin, K. H.). The Guilford Press: New York London.

[8] Costa, P.T. \& McCrae, R.R. (1992). Four ways five factors are basic. Personality and Individual Differences, 13: 653-665.

[9] Costa, P. T. \& McCrae, R.R. (1994). Stability and change in personality from adolescence through adulthood. In C. F. Halverson, Jr., G. A. Kohnstamm, \& R. P. Martin (Eds.), The developing structure of temperament and personality from infancy to adulthood. Hillsdale, NJ: Erlbaum.

[10] Crozier, W.R. (2000). Shyness and social relationships Continuity and change. Routledge: London and New York.

[11] Devaraj, S. Easley, R.F. \& Crant, J. M. (2008). How Does 
Personality Matter? Relating the Five-Factor Model to Technology Acceptance and Use. Information Systems Research, 19(1): 93-105.

[12] Dietrich, B.J. Lasley, S. Mondak, J.J. Remmel, M.L. \& Turner, J. (2012). Personality and Legislative Politics: The Big Five Trait Dimensions among U.S. State Legislators. Political Psychology, 33 (2): 195-210.

[13] Digman, J.M. (1990). Personality structure: Emergence of the Five-Factor Model. Annual Review of Psychology, 41: 417-440.

[14] Findlay, L.C. Coplan, R.J. \& Bowker, A. (2009). Keeping it all inside: Shyness, internalizing coping strategies and socio-emotional adjustment in middle childhood. International Journal of Behavioral Development, 33: 47-54.

[15] Fox, N.A. Henderson, H. A. Rubin, K.H. Calkins, S.D. \& Schmidt, L.A. (2001). Continuity and discontinuity of behavioral inhibition and exuberance: Psychophysiological and behavioral influences across the first four years of life. Child Development, 72: 1-21.

[16] Goldberg, L. (1992). The development of markers for the big-five factor structure. Personality Assessments, 4(1): 26-42.

[17] Goleman, D. (2005). Duygusal Zekâ. Çeviren: Banu Seçkin Yüksel Varlık Yayınları: İstanbul.

[18] Goleman, D. Boyatzis, R.E. \& McKee, A. (2013). Primal Leadership: Unleashing the Power of Emotional Intelligence. Boston: Harvard Business Review Press. pp.38

[19] Güngör, A. (2001). Utangaçlık Ölçeğinin Geliștirilmesi geçerlik ve güvenilirlik çalışmaları. Türk Psikolojik Danışma ve Rehberlik Dergisi, 2(15): 17-22.

[20] Hajloo, N. \& Farajian, A. (2013). Relationship between emotional intelligence and shyness. Procedia-Social and Behavioral Sciences, 84 (2013): 1180-1183.

[21] Higgs, M. \& Aitken, P. (2003). An exploration of the relationship between emotional intelligence and leadership potential. Journal of Managerial Psychology, 18(8): 814-823.

[22] Jackson, T. Fritch, A. Nagasaka, T. \& Gunderson, J. (2002). Towards explaining the association between shyness and loneliness: A path analysis with American college students. Social Behavior and Personality: An international journal, 30: 263-270.

[23] John, O.P. Hampson, S. E. \& Goldberg, L.R. (1991). The basic level in personality-trait hierarchies: Studies of trait use and accessibility in different contexts. Journal of Personality and Social Psychology, 60: 348-361.

[24] Kagan, J. Reznick, J.S. \& Gibbons, J. (1989). Inhibited and uninhibited types of children. Child Development, 60(4): 838-845

[25] Mayer, J.D. Caruso, D.R. Salovey P (2000). Emotional intelligence meets traditional standards for intelligence. Intelligence, 27: 267-298.

[26] Mayer JD, DiPaolo M. \& Salovey, P. (1990). Perceiving affective content in ambiguous visual stimuli: A component of emotional intelligence. Journal of Personality Assessment, 54: $772-781$.

[27] Mayer, J.D. \& Gaschke, Y. N. (1988). The experience and meta-experience of mood. Journal of Personality and Social Psychology, 55: 102-111.

[28] Mayer, J. D. \& Salovey, P. (1997). What is emotional intelligence? In P. Salovey and D. J. Sluyter (eds.), Emotional Development and Emotional Intelligence: 3-31. New York: Basic Books.

[29] Mayer JD, Salovey P, Caruso DR (2000). Competing models of emotional intelligence, Cambridge New York, 396-420.

[30] Mayer, J. D. Salovey, P. \& Caruso, D. R. (2008). Emotional intelligence: New ability or eclectic traits? The American Psychological Association, 63(6): 503-517.

[31] Mayer, J. D. Salovey, P. \& Caruso, D. R. (2000). Competing models of emotional intelligence. In Stenberg, R.J. (Ed.) Handbook of Human Intelligence. New York: Cambridge University Press.

[32] Mayer, J.D. Dipablo, M. \& Salovey, P. (1990). Perceiving affective content in ambiguous visual stimulating emotional intelligence. Journal of Personality Assessment, 54: 772-781.

[33] McCrae, R. R. \& Costa, P. T. (1997). Personality Trait Structure as a Human Universal. The American Psychologist, 52(5): 509-516.

[34] McCrae, R. R. \& John, O.P. (1992). An introduction to the Five-Factor Model and its applications. Journal of Personality, 60(2):175-215.

[35] Montazergheib, T. \& Ahghar, G.H. (2010). The correlation of emotional intelligence with shyness among university students. Journal of Applied Psychology, 4(12): 86-101.

[36] Mumcuoğlu, Ö. (2002). Bar-On Duygusal Zekâ Testi'nin Türkçe dilsel eşdeğerlik, güvenirlik ve geçerlik çalışması. Yüksek Lisans Tezi, Marmara Üniversitesi Eğitim Bilimleri Enstitüsü, İstanbul.

[37] Petrides, K. V. Pita, R. \& Kokkinaki, F. (2007). The location of trait emotional intelligence in personality factor space. British Journal of Psychology, 98: 273-289.

[38] Rubin, K.H. \& Asendorpf, J. B. (2014). Social withdrawal, inhibition and shyness in childhood. New York and London: Psychology Press. pp. 3-18.

[39] Ryan, T. \& Xenos S. (2011). Who uses Facebook? An Investigation into the relationship between the big five shyness, narcissism, loneliness. Computer in Human Behaviour, 27 (5): $1658-1664$.

[40] Salovey, P. \& Mayer, J.D. (1990). Emotional intelligence. Imagination, Cognition and Personality, 9: 185-211.

[41] Saucier, G. Hampson, S. E. \& Goldberg, L. R. (2000). Cross-language studies of lexical personality factors. In S. E. Hampson (Ed.), Advances in personality psychology. Philadelphia: Taylor \& Francis Inc.

[42] Schmidt, L. A. (1999). Frontal brain electrical activity in shyness and sociability. Psychological Science, 10: 316-320.

[43] Schmidt, L. A. (2003). Shyness and sociability: A dangerous combination for preschoolers. International Society for the Study of Behavioural Development. Newsletter, 1: 6-8.

[44] Schmidt, L.A. \& Buss, A. H. (2010). Understanding Shyness: Four Questions and Four Decades of Research. The 
Development of Shyness and Social Withdrawal (Ed. Coplan, R. J. \& Rubin, K. H.). The Guilford Press: New York London.

[45] Schmidt, L.A. \& Fox, N. A. (1995). Individual differences in young adults' shyness and sociability: Personality and health correlates. Personality and Individual Differences, 19: 455-462.

[46] Schutt, N. \& Maloutff, J. (2001).The Relationship between emotional intelligence and Interpersonal Relations. Journal of social psychology, 12(4):141-514.
[47] Segrin, C. \& Kinney, T. (1995). Social skills deficits among the socially anxious: Rejection from others and loneliness. Motivation and Emotion, 19: 1-24.

[48] Simmons, R.G. \& Rosenberg, F. (1975). Sex, sex roles, and self-image. Journal of Youth and Adolescence, 4: 229-258.

[49] Van Ameringen, M. Mancini, C. \& Oakman, J. M. (1998). The Relationship of Behavioral Inhibition and Shyness to Anxiety Disorder. The Journal of Nervous \& Mental Disease, 186(7): 425-431. 